JABBOUR, E. \& DANTAS. A. Brasil: considerações sobre a dinâmica ...

\title{
Brasil: considerações sobre a dinâmica política recente
}

\author{
Elias Jabbour* \\ Alexis Dantas ${ }^{* *}$
}

\section{Resumo}

Neste artigo tenta-se forjar uma síntese da dinâmica política anexo ao processo iniciado em 2003. O centro da análise encontra-se na dinâmica dos partidos políticos e das classes sociais que desembocaram numa tentativa tanto de aceleração de transição a um Novo Projeto Nacional de Desenvolvimento quanto de resistência crescente e organizada das classes dominantes. Resistência esta que se avoluma com o "cerco ao monetário" promovido pelo governo Dilma Roussef em 2012, se transforma em força política real nas manifestações de 2013 e em movimento de massa desde o início do segundo mandato de Dilma.

Palavras-chave: Dinâmica política; Governos Lula e Dilma; Novo Projeto Nacional de Desenvolvimento; Classes dominantes.

Brazil: considerations on recent political dynamics

\section{Abstract}

This article attempts to forge a synthesis of political dynamics started in 2003. The analyses core lies in the political parties and social class dynamics which resulted in an attempt both to transition

\footnotetext{
* Professor Adjunto da Faculdade de Ciências Econômicas da Universidade do Estado do Rio de Janeiro - FCE/UERJ.

* * Professor Associado da Faculdade de Ciências Econômicas da Universidade do Estado do Rio de Janeiro - FCE/UERJ.

Geosul, Florianópolis, v. 31, ESPECIAL, p 105-125, jul./dez. 2016
} 
JABBOUR, E. \& DANTAS. A. Brasil: considerações sobre a dinâmica ...

acceleration to a New National Development Project as a growing and organized resistance of the ruling classes. Resistance who gained great strenght since the "siege to monetary" promoted by Dilma Rousseff government in 2012, becomes a real political force during 2013 and in mass movement since the Dilma's second term.

Key words: Political dynamics; Lula and Dilma's governments; New National Development Project; Rulling classes.

\section{(1)}

O que se observou no Brasil pós-Lula pode se resumir em dois principais fatos, a saber: 1) o esgotamento do próprio pacto político que manteve intacto os fundamentos das políticas econômica e monetária consagradas na "Carta ao Povo Brasileiro" $(2002)^{1}$ e 2) tensões de classe advindas tanto das baixas taxas de desemprego quanto ao verdadeiro "cerco ao monetário"2 promovido no ano de 2012, notadamente nos marcos da chamada "Nova Matriz Macroeconômica". Por outro lado, um entrecruzamento de fatores políticos com questões, pretéritas, de ordem econômica são essenciais e vão desde os resultados da combinação histórica entre altas taxas de juros e câmbio valorizado até a queda dos investimentos públicos percebidas no imediato pós-Lula.

Sobre a dinâmica política, o amplo leque de alianças que levou Lula ao governo em $2002^{3}$, aliado às recorrentes crises externas que

1 O esgotamento do pacto político de 2002 pode ser lido, também, como a própria demonstração da não-funcionalidade dos pressupostos do próprio Plano Real à obtenção de maiores taxas de investimentos em relação ao PIB. Trataremos disso mais adiante.

2 Chamamos de "cerco ao monetário" a pressão exercida pelo governo Dilma no sentido de diminuição das taxas de juros e respectivos spreads bancários incorrendo - entre os meses de abril/2012 e abril/2013 - nas menores taxas de juros praticadas na história do país: 7,25\%.

3 Um ensaio de aliança com o setor produtivo nacional estava contida na própria chapa majoritária vencedora nas eleições de 2002. O vice- 
JABBOUR, E. \& DANTAS. A. Brasil: considerações sobre a dinâmica ...

atingiram o país na segunda metade da década de $1990^{4}$, transformaram a legitimidade eleitoral em grande legitimidade política o que, de maneira contraditória, não assegurou de imediato maioria congressual necessária ao governo recém-eleito ${ }^{5}$. Outro complicador estava assentado no ambiente macroeconômico. O "efeito-Lula" somado à grande vulnerabilidade externa brasileira levou a taxa de inflação, em 2002, ao patamar de 12,5\% acompanhada de grande desvalorização cambial. Em grande medida, a "Carta ao Povo Brasileiro", como visto anteriormente, antecipa uma adversa correlação de forças, induzindo o novel governo a compromissos que irão marcar - de forma profunda - a trajetória política e econômica recente, incluindo a presente crise. A aplicação imediata de uma política econômica ortodoxa estava na ordem quase natural dos acontecimentos, o que não negava per si possibilidade de transição a um novo regime interno de acumulação, como a aplicação das políticas sociais e investimentos públicos (ou com financiamento público, via BNDES) abordados anteriormente.

Acrescente-se a isso o maior protagonismo do investimento estatal, notadamente da Petrobrás e o lançamento de rudimentos de planificação do comércio externo (relações Sul-Sul) aproximando o país de grandes mercados externos, notadamente a China e a

presidente eleito, José Alencar Gomes da Silva (1931-1911) era um empresário bem-sucedido do ramo de têxteis, presidente da Companhia de Tecidos do Norte de Minas (COTEMINAS).

4 Referimo-nos às crises resultante da contenção de liquidez internacional a partir de 1997.

5 Importante notar que nas eleições de 2002, o Partido dos Trabalhadores (PT) elegeu 91 deputados federais e apenas três governadores (Acre, Mato Grosso do Sul e Piauí). Agregando o Partido Democrático Trabalhista (PDT) e o Partido Popular Socialista (PPS - que saiu do governo em meio às denúncias do "mensalão"), apoiantes em primeira hora no segundo turno das eleições, a base expandida do governo não chegava a 200 deputados num total de 513. No Senado Federal formado por 81 senadores, esta composição (base governista expandida) continha apenas 19 senadores, sendo dez do PT. 
JABBOUR, E. \& DANTAS. A. Brasil: considerações sobre a dinâmica ...

Índia $^{6}$ e as novas instituições financeiras/monetárias dos BRICS (como o Novo Banco de Desenvolvimento).

\section{(2)}

No âmbito interno, pari passu com tais movimentos de governo, o reordenamento da oposição ganha força com as primeiras denúncias de compra de votos (mensalão) e primeiras denúncias de corrupção que, num primeiro momento, mostraramse capazes de derrubar um a um os principais membros do núcleo duro do governo, notadamente o então Ministro Chefe da Casa Civil (José Dirceu) e o todo poderoso Ministro da Fazenda (Antonio Palocci). Estava forjada, neste processo, o atual e poderoso condomínio oposicionista formado sobretudo pelos três principais partidos de oposição (PSDB-DEM-PPS) e o grande conglomerado midiático. Porém, o sucesso dos programas de transferência de renda garantiu, com folga, um segundo mandato ao presidente Lula.

Esse segundo mandato desenvolveu-se na esteira de um forte crescimento econômico sob os quatro alicerces expostos. Coroouse o duplo processo relacionado entre a plena composição da base

6 A nosso ver todo esse processo não deve se restringir a uma visão estática de wage-led $\mathrm{x}$ investment-led. $\mathrm{O}$ desenvolvimento econômico é um processo cíclico que comporta momentos de maior protagonismo do consumo com outros, onde o investimento ganha força. No caso brasileiro, restringir o debate a esta falsa dicotomia pode deslocar o que há de essencial no processo. O Brasil, por exemplo, fez escolhas estratégicas em matéria de política internacional que foram essenciais ao sucesso da dinâmica inaugurada em 2003. Por exemplo, as relações Brasil-China não se restringem a uma troca desigual entre países. Afora o caráter estratégico desta relação, deve se notar os crescentes investimentos chineses no país desde então; além das possibilidades abertas de financiamento pelo recém-formado Novo Banco de Desenvolvimento (comumente chamado de Banco do BRICS). Essa viragem na diplomacia brasileira também deve ser objeto de análise à presente crise política. 
JABBOUR, E. \& DANTAS. A. Brasil: considerações sobre a dinâmica ...

do governo, já com a importante presença do PMDB, com o de isolamento da oposição, apesar da crescente força de seu braço principal, a mídia. Qual a grande impressão passada deste período, além da aparência? Seria o sucesso dos governos Lula algo explicado somente pelo efeito demanda provocado pela China acrescido por notáveis programas sociais? Qual o grande acerto em matéria de política a ser realçado?

$\mathrm{Na}$ tentativa de superar as visões estilizadas sobre o período é instigante perceber que, sim, os dois mandatos de Lula devem ser inseridos num contexto de transição do neoliberalismo a um Novo Projeto Nacional Brasileiro. Transição neste sentido deve ser compreendida como um processo de unidade de contrários entre um velho que persiste e novos elementos capazes de projetar um salto. Se no velho estão contidas as institucionalidades consagradas na década de 1990 (por exemplo, a política de metas de inflação e o "tripé macroeconômico") e na "Carta ao Povo Brasileiro", o novo ganha força arremetido pela crise financeira internacional cujo enfrentamento suscitou o fortalecimento de instituições como o BNDES, a Petrobrás, o mercado interno de capitais e de relações mais diversificadas com o resto do mundo, incluindo amplo protagonismo brasileiro em todos os fóruns internacionais ${ }^{7}$.

7 Se relacionarmos o grau de independência nacional de um país com sua capacidade interna de financiamento da produção é notável o fato de a Petrobrás ter realizado a maior operação de captação do mundo no mercado de capitais nacional. No final de setembro de 2010 esta mesma empresa captou cerca de US\$ 70 bilhões na BOVESPA. Tratou-se da "maior operação de captação do mundo" até então. O fato é uma alvissara diante de determinados fatos e processos históricos. Por exemplo, entre 1998 e 2002, o Brasil recorreu três vezes ao Fundo Monetário Internacional. Por outro lado, em 2009 o Brasil passou a ser credor desta instituição. Algo inimaginável, diga-se de passagem. Expressão de um ensaio de transição. 
JABBOUR, E. \& DANTAS. A. Brasil: considerações sobre a dinâmica ...

\section{(3)}

Os dois governos Lula marcaram uma ruptura em meio à continuidade. Reprisou transições anteriores, notadamente as relacionadas aos processos de Independência (1822), Abolição/República (1888-89) e a Revolução de 1930. Todas caracterizadas por "meias rupturas" levadas adiante por amplas maiorias políticas, heterogêneas ${ }^{9}$. Diante de uma correlação de forças adversa Lula demonstrou capacidade política de ampliação com a formação de um governo heterogêneo unindo desde forças claramente ortodoxas (Banco Central) até desenvolvimentistas convictos (José de Alencar), porém com um núcleo programático muito claro que envolveu desde políticas sociais incisivas a uma política comercial agressiva.

Mas o ponto forte de um governo - claramente de coalizão carrega dentro de si sua própria fragilidade, muitas vezes residente não somente na esteira das forças políticas em movimento. Vale destacar ao menos três pontos de fragilidade. A primeira delas é a própria fluidez das forças políticas arregimentadas em torno do presidente Lula, notadamente o PMDB. Se por um lado, com o apoio desta força tornou-se possível colocar em execução programas sociais com alto grau de profundidade, inclusive política $^{10}$, por outro a própria complexidade desta força foi ficando

8 Sobre essa dinâmica histórica/política brasileira de "meias rupturas", ler: RANGEL, I.: A história da dualidade brasileira. In: RANGEL, I.: Obras Reunidas. v. 2. Rio de Janeiro: Contraponto, 2005.

9 Sobre as transições brasileiras capitaneadas por maiorias heterogêneas, ler: REBELO, A.: A chave das maiorias heterogêneas. Princípios. Ed. 68. Fev/Mar, 2003. pp. 20-21.

10 É irresistível perceber a queda da influência do antigo PFL, hoje Democratas, em sólidos redutos eleitorais - notadamente na Região Nordeste. Causa e consequência dos programas de transferência de renda e maciços programas de investimento na citada região. A região Nordeste foi a que mais cresceu no país entre 2003 e maio de 2014 a região aumentou seu PIB em 58\% frente a média nacional de 48\%. Em 2012, sua participação no PIB nacional chegou ao seu maior índice histórico, 13,5\%. 
JABBOUR, E. \& DANTAS. A. Brasil: considerações sobre a dinâmica ...

evidente na mesma proporção em que a economia passou a emitir sinais de esgotamento, sobretudo no interregno entre os anos de 2012 até o presente momento ${ }^{11}$.

O segundo ponto de fragilidade pode estar na possibilidade de menosprezo, por parte do governo, da capacidade da oposição se reagrupar e o papel conferido à grande mídia neste processo. É notória a percepção para quem a mídia tornou-se, desde 2005, grande elemento de desestabilização e que claramente substituiu os apequenados partidos de oposição na condução - e tentativa - de desconstrução dos feitos dos governos liderados por Lula. O sucesso dos programas sociais e o consequente crescimento econômico certamente deslocou o governo de medidas estratégicas e com puro sentido de aprofundamento democrático, entre estas medidas não há dúvidas sobre a centralidade da reforma da mídia, tendo em vista a capacidade de subversão da subjetividade que dela emana e que assistimos, com mais intensidade, hoje.

Por fim, o terceiro ponto encerrado nos compromissos resumidos na "Carta ao Povo Brasileiro" e as contradições - cada vez mais latentes - entre os estertores da transição de uma dinâmica de formação prévia de poupança, logo proibitiva ao investimento, à outra, mais centrada no consumo e no investimento. Uma nova ordem institucional surgia em plena contradição com outra, pretérita $^{12}$. A combinação entre um

${ }^{11}$ A nosso ver, sobre o PMDB, não guarda serventia caracteriza-lo como uma força de caráter puramente fisiológica ou coisas do tipo. A compreensão da dinâmica política do PMDB guarda mais profundidade ao analisar sua história, composição e prática em correspondência com o caráter complexo do Brasil e as diferentes dinâmicas de classes sociais percebidas, regionalmente.

${ }_{12}$ Um quadro contendo os componentes institucionais da dinâmica de acumulação implementado na década de 1990 pode ser encontrado em: BRUNO, M. Ortodoxia e Pseudodesenvolvimentismo: nunca dantes uma receita foi tão infeliz. Insight Inteligência. Abril, Maio, 
JABBOUR, E. \& DANTAS. A. Brasil: considerações sobre a dinâmica ...

programa de governo voltado à geração de empregos e abertura de mercados externos com a necessidade de cumprimento de metas fiscais e de inflação gerou deformações que somente a superação da institucionalidade pretérita seria capaz de enfrentar. Os números são sugestivos: a relação investimentos x PIB, e seus respectivos picos nos terceiros trimestres de cada ano, desde 2002, nunca foi maior do que $20 \%$. Sendo a maior média anual do período registrada em 2010 (19,46\%).

A utilização da taxa de câmbio, como forma de compensar (para fins de combate à inflação) a queda da taxa de juros a partir de 2006, levou a balança comercial da indústria de transformação de superávit da ordem de US\$ 24,06 bilhões em 2004, para deficitária em US\$ 63,5 bilhões em $2014^{13}$. O primeiro plano distante da superfície da análise do processo está na combinação histórica entre altas taxas de juros e valorização cambial, variável última que chegou à casa do US\$ $1=\mathrm{R} \$ 1,50$ no crepúsculo do segundo mandato do presidente Lula e com a variável juros prenunciando o fim da era do wage-led $^{14}$. A taxa SELIC ajustada

Junho/2015. p. 94-105. Este "choque de institucionalidades" foi por nós tratado em: JABBOUR, E.; DANTAS, A. : O presente e o futuro do capitalismo brasileiro em Ignacio Rangel. Artigo no prelo em homenagem à Ignacio Rangel à publicação editada pelo BNDES/ABDE em alusão ao centenário de Ignacio Rangel e Rômulo Almeida.

13 Déficit na indústria atinge US\$ 63,5 bilhões em 2014. Valor Econômico. 24/02/2015. É evidente que a superação desta ordem punitiva à indústria e ao investimento demanda a combinação entre baixas taxas de juros e câmbio desvalorizado, algo complicado diante de uma institucionalidade que coloca o combate à inflação via compressão da demanda à frente. A lógica desta institucionalidade demanda, no máximo, contrapartida em um dos dois preços básicos. Redução da taxa de juros reclama valorização cambial. Desvalorização cambial deve ser precedida por altas taxas de juros, como temos observado nos dias de hoje.

${ }_{14}$ Ainda que tenhamos reduzido substancialmente a taxa de juros desde 2006, a mesma ainda era demasiadamente alta em comparação aos padrões internacionais. Neste espaço não trataremos desta controvérsia 
JABBOUR, E. \& DANTAS. A. Brasil: considerações sobre a dinâmica ...

não somente à precificação da moeda, mas também como referência geral de preços torna-se o principal elemento de inércia da economia.

\section{(4)}

Mudanças de dinâmica de acumulação devem ser precedidas por alterações profundas de ordem política/institucional. Existem questões em aberto, e que apesar da curta distância histórica, não devemos tentar nos furtar em buscar respostas. Será que não se aproveitou a oportunidade aberta pela crise financeira internacional, e a consequente defensiva neoliberal, à superação dos marcos fundamentais do Tripé Macroeconômico?

Uma difícil resposta. Importante fazermos menção a alguns fatos e uma conjuntura. A primeira medida do governo, em outubro de 2008, foi anunciar uma saída pelo campo fiscal com a redução do superávit primário. Por outro lado, a demora na queda da taxa de juros fora compensada com uma queda em cinco pontos percentuais durante todo o ano de 2009. Uma grande, e acertada, aposta fora anunciada em março de 2009 com o lançamento de um imenso programa habitacional, o "Minha Casa, Minha Vida". Tais movimentos indicavam o fortalecimento do campo desenvolvimentista dentro do governo numa clara mudança em relação a um início de primeiro mandato marcado por forte aperto fiscal e monetário. Logo, a questão não é somente de velocidade da transição, mas - principalmente - de profundidade.

Qual o ambiente interno a uma mudança desta magnitude quando o crescimento do PIB atingiu - em pleno ano eleitoral - a casa dos 7,5\%; a taxa de desemprego, 6,7\% e a inflação, 5,9\% portanto da dentro da meta "cheia" - e com a popularidade do presidente alcançando o pico de $87 \%$ ? A necessária visão de estadista, daquele capaz de enfrentar contradições políticas e estratégicas de fundo, indicando rumos, pode ter sido nublada pelo espontaneísmo do próprio estadista. Ao indicar o rumo da envolvendo a desindustrialização recente, ou não, do país. 
JABBOUR, E. \& DANTAS. A. Brasil: considerações sobre a dinâmica ...

ampliação da parcela do consumo em relação ao PIB, Lula arremeteu ao seu passado de operário atingido duramente pelas crises de 1973 e 1979 e do político popular à frente da resistência às políticas antissociais da década de 1990. Certamente, a visão estratégica - do problema estratégico anexo às institucionalidades consagradas na década de 1990 - foi prejudicada.

\section{(5)}

Por mais paradoxal que seja, a substituição de Lula por Dilma ensejou um reagrupamento da oposição. Em certa medida o cálculo mostrou correção. Afinal Dilma não carregava em si o carisma e o símbolo encerrados em Lula. Ao contrário, a postura de gerente atribuída a ela pelo ex-presidente também poderia refletir, e refletiu, uma percepção de pouca afeição à política da sucessora. Algo que provaria ser fatal num país cuja história atesta a necessidade de amplitude e necessidade de grandes arranjos políticos à sustentação de determinados pactos políticos. A crise política que nos assola atualmente guarda raízes justamente no quase desmoronamento da frente política que sustentou o projeto vitorioso nas eleições de 2002. Esta possibilidade refletida na personalidade dura da presidente Dilma foi amplamente explorada. Ao lado disso, a oposição num processo continuo e calculado de acúmulo de forças ancorado na grande mídia, conseguiu angariar a simpatia de uma classe média sensível a temas de cunho moral, sendo a principal delas a questão da corrupção ${ }^{15}$.

Ao que tudo indica, Dilma Roussef, talvez numa ação coordenada com o próprio ex-presidente Lula, tenha partido à recuperação da classe média. Por exemplo, pressionada pela mídia,

15 José Serra (PSDB), o candidato derrotado no segundo turno das eleições de 2010 , obteve $43,95 \%$ dos votos válidos, enquanto Geraldo Alckmin, suplantado por Lula no segundo turno em 2006, contou com $39,17 \%$ dos votos. Esse processo de acúmulo de forças é consagrado nas eleições gerais de 2014 quando Aécio Neves obtém 48,3\% dos votos válidos. 
JABBOUR, E. \& DANTAS. A. Brasil: considerações sobre a dinâmica ...

somente no primeiro ano de governo seis ministros foram demitidos após denúncias de corrupção. Nesta esteira, além do ambiente econômico estável, sua popularidade alcançou $64 \%$ de aprovação (ótimo ou bom) em abril de 2012. Pode-se sugerir que o início de uma ofensiva conservadora tenha atingido as decisões governamentais macro desde o final de 2010.

$\mathrm{O}$ movimento da taxa SELIC voltou à ascendente no mês de fevereiro de 2010 quando saiu de 8,5\% para 12,5\% em agosto de $2011^{16}$, num movimento de contração do crédito auxiliado (desde 2011) por medidas macroprudenciais. No final deste mesmo ano o governo decidiu elevar fortemente a meta de superávit primário para 3,1\% do PIB em 2011. Segundo SERRANO E SUMA (2015, p. 1):

"This rapid increase in the primary surplus was only possible thanks to a strong reduction in the growth of public spending. In 2011, public investment, both of the central government and the state-owned companies, fell dramatically, by 17.9 percent and 7.8 percent in real terms, respectively. The government's contractionary policies led to a pronounced decline in private investment as well, so that total investment (public and private) fell sharply. After growing at an average annual rate of 8.0 percent between 2004 and 2010, peaking at 18 percent in 2010, gross fixed capital formation over 2011-2014 grew by just 1.8 percent annually"

Esta decisão - ao lado das citadas demissões - consolidaram o processo de acúmulo de forças por parte da oposição. O mais interessante: em um momento de claro desgaste das concepções neoliberais no mundo e no Brasil e após o sucesso de uma orientação interna de combinação entre aumento dos investimentos públicos e expansão do consumo. Outro aspecto é o rumo da transição indicado, sobretudo a partir do segundo mandato de Lula,

${ }^{16}$ Banco Central do Brasil. 
JABBOUR, E. \& DANTAS. A. Brasil: considerações sobre a dinâmica ...

e a questão da oportunidade (ou não) perdida de superação da ordem institucional implantada na segunda metade da década de 1990. Neste mister, certamente o aumento da taxa de juros, o anúncio de medidas macroprudenciais e a elevação do superávit primário podem indicar uma chance perdida num momento de grande força e prestígio tanto de Lula quanto de Dilma. E quando, talvez, intentou-se um experimento desta magnitude, sobretudo a partir de 2012, o timing político pode ter-se esvaído.

Surpreendentemente, o final do governo Lula e o início de Dilma marcaram um rompimento de cerco ao neoliberalismo nacional, denunciando que as políticas expansionistas poderiam ter tido hora de início e término e que o Brasil deveria manter o rumo estratégico indicado nos anos de 1994 e 1999. Ao menos essa viragem do segundo semestre de 2010 até o início de 2012 pode sugerir essa indicação numa coincidência de fatores políticos, econômicos e institucionais que marcaram o início de um fulminante processo de acúmulo de forças por parte da oposição, capitaneada por seu braço midiático ${ }^{17}$.

\section{(6)}

Os impressionantes acontecimentos iniciados em maio de 2013 até o resultado eleitoral de 2014 são um vasto material de análise ainda pouco explorado. Segundo SINGER (2015, p. 44):

"De 2011 a 2012, em iniciativa política inesperada, os desenvolvimentistas invadiram a cidadela sagrada das decisões monetárias e avançaram aos saltos, pressionando instituições privadas para reduzirem os próprios ganhos, com o apoio das divisões pesadas dos bancos públicos e de ousada mudança nas regras da poupança. Quando a refrega parecia ganha, (...), o poderoso Banco Central (BC) voltou a elevar a taxa SELIC (abril de 2013) e, na prática, devolveu ao mercado financeiro controle sobre parte

17 A pressão exercida pela inflação pode ser outro elemento a ser destacado. A inflação de 2011 foi de 5,9\%, a maior desde 2006. 
JABBOUR, E. \& DANTAS. A. Brasil: considerações sobre a dinâmica ...

fundamental da política econômica. A decisão tornava manca a perspectiva de retomada do desenvolvimento nacional (...)"

Esta passagem é suficiente ao levantamento de - ao menos três questões. A primeira, o alcance do avanço proposto com a inauguração da "Nova Matriz Macroeconômica"18 em 2012 deveria sugerir um imenso acúmulo de forças da parte do campo político liderado pelo PT que na verdade ocorreu rapidamente após a crise financeira internacional, porém sustada desde o segundo semestre de 2010. A ousada proposta de mudança na condução econômica, neste sentido; por ser inesperada, não foi precedida por preparo político prévio, talvez por menosprezar o grau de batalha à espreita. A subestimação da capacidade de reagrupação política do campo conservador mostrou-se fatal. A derrota da curta experiência, avassaladora ${ }^{19}$.

${ }^{18}$ A "Nova Matriz Macroeconômica" sugeria um maior protagonismo do Estado na condução da política econômica. Na prática redundou numa queda da taxa de juros de $12,5 \%$ para $7,25 \%$ entre abril de 2011 e abril de 2013, certamente pressionada pela presença dos bancos públicos no mercado de crédito. Ampla atuação do BNDES que no segundo mandato da presidente Dilma desembolsou cerca de R\$ 400 bilhões, intervenção governamental no sistema de preços do setor elétrico, desonerações fiscais e controle sobre o fluxos de capitais e políticas de conteúdo nacional e lenta desvalorização do real frente ao dólar. O rumo desta mudança radical estava no correto diagnóstico para quem a manutenção do progresso social obtido nos anos Lula demandava crescimento econômico anual da ordem de $5 \%$.

19 Neste tocante, a seguinte citação de SINGER (2015, p. 44) guarda imenso significado: "A perspectiva de acelerar o lulismo acaba por produzir a maior crise econômica desde 1992, com desemprego em massa e queda na renda dos trabalhadores. Vencida e humilhada, a antiga chefe das hostes desenvolvimentistas, agora reduzida a $13 \%$ da 'popularidade', não consegue sequer usar a rede obrigatória no Primeiro de Maio de 2015, temerosa de provocar panelaço semelhante ao que ocorrera, um mês e meio antes, por ocasião de pronunciamento 
JABBOUR, E. \& DANTAS. A. Brasil: considerações sobre a dinâmica ...

A segunda que deve se inserir na passagem que incide sobre a "devolução" - em abril de 2013 - ao mercado financeiro, pelo $\mathrm{BC}$, do controle sobre "parte fundamental da política econômica". Esta devolução de poder ao mercado financeiro é parte de um todo que envolve a própria tomada, pelos liberais, do aparelho de Estado - sobretudo após o processo de redemocratização na metade da década de 1990, a eleição de Collor e os dois mandatos de Fernando Henrique Cardoso. Não deve parecer surpresa que a oposição a políticas de cunho inclusivas e desenvolvimentistas partiriam de quadros internos ao aparelho de Estado $^{20}$. Causa perplexidade perceber que instituições forjadas ao esforço desenvolvimentista da era getulista se tornaram esteio institucional legitimador a opiniões de economistas do campo liberal e ultraliberal, sobretudo o Instituto de Pesquisa Econômica Aplicada (IPEA) e o Banco Nacional de Desenvolvimento Econômico e Social (BNDES). O Banco Central, neste sentido, seria somente expressão de um bunker antidesenvolvimentista pronto a articular um dumping sobre o Estado, a partir do próprio Estado ${ }^{21}$.

$\mathrm{O}$ terceiro ponto diretamente relacionado com o comportamento dos empresários. Interessante notar que em grande medida a "Nova Matriz Macroeconômica" foi ao encontro de demandas há muito colocadas por empresários, sobretudo os ligados a Federação das Indústrias do Estado de São Paulo (FIESP). Um diálogo inédito, em 2011, entre a própria FIESP e as centrais sindicais produziu um documento pontuando as medidas necessárias à contenção da regressão industrial verificada desde a

relativo ao Dia da Mulher".

20 Trata-se de uma temática que deverá guardar centralidade à compreensão da dinâmica política nacional.

${ }^{21}$ Escrevemos sobre este fenômeno anteriormente, em: JABBOUR, E.: Plano Real (1994): o banditismo de Estado no poder. Portal Vermelho, 07/04/2014. Disponível em: http://www.vermelho.org.br/ coluna.php? id_coluna_texto $=5871 \&$ id_coluna $=17$ 
JABBOUR, E. \& DANTAS. A. Brasil: considerações sobre a dinâmica ...

década de $1990^{22}$. Porém, o que se verifica no desenrolar do processo foi um lento, porém firme, distanciamento do empresariado em relação ao governo - a ponto de se tornar uma das bases de apoio ao impedimento da presidente Dilma.

\section{(7)}

Outras questões que em si já estão contidas possíveis respostas: em 2011, ao "retirar" do sistema financeiro a prerrogativa de determinar o preço da moeda, não estaria o governo indo ao encontro dos interesses do setor produtivo, tendo em vista uma possível contradição de classe entre os setores produtivo e financeiro? Ou faltou ao governo uma leitura exata da transmutação do grande empresário industrial em rentier, dada a natureza da própria dinâmica de acumulação inaugurada na década de 1990, acrescida de uma firme resposta destes mesmos empresários ao processo de fortalecimento da classe trabalhadora como causa e consequência de uma situação de quase pleno emprego ? $^{23}$

A transformação da contraofensiva conservadora de uma guerra de posição ao patamar de guerra de movimento necessitava de certo apelo capaz de mobilizar a classe média que desde as eleições de 2010 se deslocava do governo. A formação de uma sólida base social estava na ordem dos acontecimentos. A

22 Trata-se do texto, Brasil do diálogo, da produção e do emprego. Federação das Indústrias do Estado de São Paulo. Disponível em: http://www.fiesp.com.br/brasil-do-dialogo-pela-producao-e-emprego/

23 Amparado em estudos do professor Ruy Braga, André Singer aponta o aumento do poder de barganha da classe trabalhadora o que, per si, guarda motivo suficiente a um afastamento do capital industrial, seja do governo, seja de uma linha tênue de aliança com os trabalhadores conforme se lê (SINGER, 2015, p. 65): "O número de paralisações, que já vinha subindo desde 2008, atingiu quase 87 mil horas paradas em 2012, o maior índice desde 1997, e continuou a crescer. Segundo Braga, houve 873 greves em 2012 com um salto para mais de 2 mil em 2013”. 
JABBOUR, E. \& DANTAS. A. Brasil: considerações sobre a dinâmica ...

oportunidade surgira com a eclosão das manifestações de junho de 2013. O movimento inicia-se como contestação a aumentos da tarifa de ônibus, primeiramente em São Paulo. Transbordando para pautas avessas ao Estado e, consequentemente, a política ${ }^{24}$.

As manifestações de junho assentam dois movimentos que foram fundamentais ao isolamento do governo e o fim da experiência da "Nova Matriz Macroeconômica". O primeiro movimento foi o de desembarque do empresariado produtivo do governo, agora em aliança aberta com o rentismo. $\mathrm{O}$ segundo diretamente relacionado com a captura das manifestações pela mídia que tardou a abraçar as possibilidades abertas pelo movimento, e ao abraça-las tratou-a de despolitiza-la e utiliza-la no sentido de pautar ao governo a necessidade de mudanças profundas na política monetária. A retórica contra a política e os políticos atingiu seriamente a popularidade da presidente. Antes das manifestações o "ótimo e bom" que era de 65\% em março de 2013 caiu para $30 \%$ no final dos protestos ${ }^{25}$.

O cerco ao desenvolvimentismo fora consolidado. A reação do governo atesta isso, conforme SINGER (2015, p. 56-57) ${ }^{26}$ :

24 Evidente que a ascensão aos mercados de trabalho e consumo de milhões de famílias desde 2003 tenderia a demandas por maior mobilidade urbana e de serviços públicos de qualidade. $\mathrm{Na}$ verdade, o início das manifestações denunciava uma clara rebelião das relações de produção com as forças produtivas, neste caso mais uma expressão da transformação da crise agrária de superpopulação em crise urbana, também, de superpopulação.

25 Popularidade de Dilma cai 27\% após protestos. Folha de S. Paulo, 29/06/2013. Disponível em: http:/www1.folha.uol.com.br/poder/ 2013/06/1303541-popularidade-de-dilma-cai-27-pontos-aposprotestos.shtml

26 Uma análise análoga a de Singer, e mais recente (às vésperas da votação do impeachment na Câmara dos Deputados), foi elaborada por Perry Anderson: Crisis in Brazil. London Review of Books. V. 38, n 38. 21 April 2016. 
JABBOUR, E. \& DANTAS. A. Brasil: considerações sobre a dinâmica ...

"Ao reagir à onda de protestos, Dilma propôs a responsabilidade fiscal como o primeiro dos cinco pactos que deveriam reunificar a nação e, no final de julho de 2013, promoveu um corte de 10 bilhões de reais no orçamento de 2013, 'em resposta, sobretudo, ao mercado financeiro, que o acusa [ao governo] de leniência com a inflação'. No começo de 2014, o gasto público foi outra vez cortado, abandonando-se o projeto de lei que reduzia as dívidas de estados e municípios. A prefeitura estratégica comandada por Haddad viu-se estrangulada, pondo em perigo o futuro da gestão. Some-se à contenção dos gastos públicos os juros sempre em elevação, e será compreensível que o crescimento do pib em 2014 tenha sido zero. A política monetária e fiscal contracionista, junto com a profunda desconfiança da burguesia, anulara as tentativas da nova matriz de elevar o investimento, o qual apresenta uma queda de 4,4\% em 2014. Com o declínio da atividade econômica, cai a arrecadação, deixando o Estado vulnerável às propostas de ajuste físcal que se tornarão ubíquas".

Os passos seguintes deste processo foram marcados por uma precipitação de acontecimentos que levaram ao impeachment da presidente Dilma Roussef. Prejudicada por movimentos audaciosos do presidente da Câmara, Eduardo Cunha - que por sua vez contou com uma ampla unidade tática da oposição em torno do impeachment ${ }^{27}$, da amplificação just in time dos primeiros resultados da Operação Lava Jato e de um processo de transformação em movimento de massas de um movimento de

27 À análise deste processo guarda centralidade o acordo de unidade tática da oposição tendo em vista que durante boa parte da crise política uma unidade estratégica em torno da necessidade de deslocar as forças sustentadoras do projeto vencedor em 2002, 2006, 2010 e 2014 nunca fora acompanhada por uma unidade de caráter tática. Unidade esta que redundou num consenso conservador em torno da necessidade de impedimento da presidente da República. 
JABBOUR, E. \& DANTAS. A. Brasil: considerações sobre a dinâmica ...

características ultraconservadoras -, teve seu governo enfraquecido e em rápido processo de isolamento político e institucional ${ }^{28}$.

\section{(8)}

Um senso comum paira sobre o país quando o assunto é a crise política que culminou no impedimento da presidente Dilma Roussef. É recorrente o parti pris para quem a crise política é decorrência de uma crise econômica, que por sua vez, tem na crise fiscal sua face mais visível. Se existe alguma ponta de verdade nesta afirmação, ela deve ser buscada numa atitude que variou da euforia à extrema hostilidade por parte do empresariado com as induções indicadas na "Nova Matriz Macroeconômica" e as desonerações fiscais anexas a uma política de troca do investimento público pelo seu congênere privado ${ }^{29}$. Até então - é evidente, como demonstrado neste artigo -, que os números da economia brasileira até 2014 não servem de base a uma explicação convincente sobre as causas da crise política.

A presente crise fiscal deve ser vista sob um ângulo latu sensu, o que significa abrir mão da ciência econômica vista como

28 Existem características brasileiras no que se refere à situação de "isolamento político-institucional” da presidente da República. Na verdade, uma visão larga da referida situação deverá remeter ao papel exercido por órgãos de Estado no processo, notadamente o poder judiciário, o Ministério Público e a Polícia Federal. Órgãos estes compostos - em sua maioria - por membros advindos da pequena burguesia de grandes centros urbanos. Com forte viés moralista tiveram papel de proa ao formar uma unidade em torno das investigações da Operação Lava Jato conduzida por um juiz de primeira instância (Sérgio Moro), habitué de cursos de formação contra crimes fiscais oferecidos pelo Departamento de Estado dos EUA, influenciado pela experiência da Operação Mãos Limpas (Itália). Na ponta do processo podemos, tranquilamente, admitir que houve um golpe institucional levado a cabo por aparelhos do próprio Estado cujos processos judiciais naturalizaram práticas dignas de um verdadeiro estado policial, de exceção.

${ }^{29}$ Conforme já indicado, a troca dos investimentos públicos por políticas típicas pelo "lado da oferta" tornou-se um erro estratégico fatal. 
JABBOUR, E. \& DANTAS. A. Brasil: considerações sobre a dinâmica ...

$\overline{\text { um sistema fechado de ações (Economia Clássica e Neoclássica) à }}$ uma ótica de redundância da dinâmica das classes sociais no processo de produção, circulação e distribuição (Economia Política). A crise fiscal, assim sendo, também - e principalmente é produto de uma deliberada ação do empresariado ${ }^{30}$ que ao não responder as induções governamentais (pela via das desonerações fiscais, por exemplo) postou-se na linha de frente da coalisão conservadora, encetando uma crise econômica de dimensões gigantescas e criando as condições objetivas ao sucesso de uma empreitada de caráter golpista.

Uma verdadeira resposta ao aumento do poder aquisitivo da população e a situação de ampla empregabilidade causada pela crescente ação do Estado na economia, conforme demonstrado nos gráficos inseridos na primeira seção deste artigo. Algo que já nos alertava KALECKI (1943, p. 327) em uma citação que deverá nos obrigar a uma reflexão mais profunda sobre a verdadeira essência da presente crise brasileira:

“(...) the maintenance of full employment would cause social and political changes which would give a new impetus to the opposition of the business leaders. Indeed, under a regime of capitalist full employment, the 'sack' would cease to play its role as a disciplinary measure. The social position of the boss would be undermined, and the self-assurance and classconsciousness of the working class would grow. Strikes for wage increases and improvements in conditions of work would create political tension. It is true that profits would be higher under a regime of full employment than they are on the average under laissez-faire; and even the rise in wage rates resulting from the stronger bargaining power of the

30 Algo reconhecido, inclusive, por Marcos Lisboa - um dos principais nomes da ortodoxia brasileira. 'Setor privado cavou essa crise', diz Marcos Lisboa, presidente do Insper. O Estado de S. Paulo, 07/12/2015. Disponível em: http://economia.estadao.com.br/noticias/geral,setorprivado-cavou-essa-crise--diz-marcos-lisboa--presidente-doinsper, 10000004079 
JABBOUR, E. \& DANTAS. A. Brasil: considerações sobre a dinâmica ...

workers is less likely to reduce profits than to increase prices, and thus adversely affects only the rentier interests. But 'discipline in the factories' and 'political stability' are more appreciated than profits by business leaders. Their class instinct tells them that lasting full employment is unsound from their point of view, and that unemployment is an integral capital the 'normal' capitalist system".

\section{Referências bibliográficas}

ANDERSON, P.: Crisis in Brazil. London Review of Books. V. 38, no 38. 21 April 2016.

BRUNO, M. Ortodoxia e Pseudodesenvolvimentismo: nunca dantes uma receita foi tão infeliz. Insight Inteligência. Abril, Maio, Junho/2015. p. 94-105.

JABBOUR, E.; DANTAS, A.: O presente e o futuro do capitalismo brasileiro em Ignacio Rangel. Artigo no prelo em homenagem à Ignacio Rangel à publicação editada pelo BNDES/ABDE em alusão ao centenário de Ignacio Rangel e Rômulo Almeida.

KALECKI, M.: Political Aspects of Full Emplloyment. The Political Quaterly. V. 14, Issue 4. Oct 1943. pp. 322-330.

RANGEL, I.: A história da dualidade brasileira. In: RANGEL, I.: Obras Reunidas. v. 2. Rio de Janeiro: Contraponto, 2005.

REBELO, A.: A chave das maiorias heterogêneas. Princípios. Ed. 68. Fev/Mar, 2003. pp. 20-21. 
JABBOUR, E. \& DANTAS. A. Brasil: considerações sobre a dinâmica ...

SERRANO, F.; SUMMA, R.: Aggregate Demand and the Slowdown of Brazilian Economic Growth from 2011-2014. Center for Economic and Policy Research. August, 2015.

SINGER, A.: Cutucando onças com varas curtas. Novos Estudos. 102. Jul/2015. pp. 43-71.

\section{Matérias em jornais e links:}

Déficit na indústria atinge US\$ 63,5 bilhões em 2014. Valor Econômico. 24/02/2015.

Popularidade de Dilma cai 27\% após protestos. Folha de S. Paulo, 29/06/2013. Disponível em: http://www1.folha.uol.com.br/poder/2013/06/1303541popularidade-de-dilma-cai-27-pontos-apos-protestos.shtml

JABBOUR, E.: Plano Real (1994): o banditismo de Estado no poder. Portal Vermelho, 07/04/2014. Disponível em: http://www.vermelho.org.br/coluna.php? id_coluna_texto $=5871 \&$ id_coluna $=17$

Brasil do diálogo, da produção e do emprego. Federação das Indústrias do Estado de São Paulo. Disponível em: http://www.fiesp.com.br/brasil-do-dialogo-pela-producao-eemprego/

'Setor privado cavou essa crise', diz Marcos Lisboa, presidente do Insper. O Estado de S. Paulo, 07/12/2015. Disponível em: http://economia.estadao.com.br/ noticias/geral,setor-privado-cavou-essa-crise--diz-marcoslisboa--presidente-do-insper, 10000004079. 
JABBOUR, E. \& DANTAS. A. Brasil: considerações sobre a dinâmica ...

Recebido em Aceito em 